\title{
Tarjetas de presentación e identidad. Las colecciones de relatos integrados desde los umbrales
}

\author{
José Sánchez Carbó \\ Universidad Iberoamericana Puebla
}

\section{Resumen}

Este artículo atiende la solicitud que Gerard Genette plantea en Umbrales sobre la necesidad de analizar género por género las funciones del paratexto. Así, se revisará la función de los paratextos en las colecciones de relatos integrados porque en estos márgenes se ubican claves que anticipan una intención estructural o temática del autor y una forma de lectura propias de la modalidad. En este sentido, de la amplia gama de paratextos, se intentará definir cuáles y cómo contribuyen de forma consistente a prolongar las ideas del autor, reconocer sus efectos en el lector y definir la peculiaridad de la colección integrada.

Palabras clave: Colección de relatos integrados, ciclo de cuentos, secuencia cuentística, paratextos, cuento hispanoamericano siglo XX.

\section{Abstract}

This article was motivated by the urgent need of analyzing the function of paratexts in every genre, expressed by Gerard Genette in Paratexts, Thresholds of interpretation. Therefore, it is devoted to the review of the paratext's functions in collections of short stories. This genre provides us with some key ideas related to the author's intentions regarding structure or topic and reading. This article selects some paratexts to define which of them contribute to extend the author's ideas 
and how this is accomplished; to recognize the effects on the reader and to define the uniqueness of the collections of short stories.

Keywords: Collections of Short Stories, Short Story Cycle, Short Story Sequence, Paratexts, Hispano-American short stories of the $20^{\text {th }}$ century.

$\mathrm{Z}$ n las colecciones de relatos integrados los paratextos, sean autorales, editoriales, públicos o privados, anticipan una intención del autor, estructural o temática; representan una estrategia de promoción editorial y contribuyen, condicionan o determinan una forma de lectura. Ya sea a través del título, del prefacio o de la entrevista el autor manifiesta la singular integración del conjunto de relatos; en los textos editoriales el editor ubica el texto en un campo genérico intermedio entre la novela y el libro de cuentos; y en las reseńas el crítico describe la forma y los elementos que integran los relatos. Este conjunto de textos, como veremos, si bien cumplen una función enfática e informativa, no resultan marginales; sobre todo, cuando son propuestos por el autor.

Las colecciones de relatos integrados son una modalidad narrativa que en las últimas tres décadas ha llamado la atención de la crítica. Se reconoce también como ciclo de cuentos (Ingram, 1971; Mann, 1989), secuencia cuentística (Luscher, 1989; Kennedy, 1995), cuentos compuestos (Lundén, 1999), colecciones de cuentos entramados (Leal, 2006) o novela compuesta (Dunn y Morris, 1995). Esta modalidad, a veces considerada género narrativo, independientemente del nombre y de las singularidades implícitas de cada propuesta, en términos generales, se caracteriza por la repetición o recurrencia de personajes, espacios, formas narrativas o motivos y la simultánea interrelación y autonomía de cada uno de sus relatos o, en palabras de Rolf Lundén (1999), por equilibrio entre integración y desintegración de las partes. 
La teoría y la crítica relativa a esta modalidad ha distinguido elementos esenciales de otros auxiliares o marginales, lo cual no indica que estos últimos sean prescindibles, ya que en principio delinean su fisonomía o anuncian una peculiaridad. Miguel Gomes, atento a estas distinciones, estudió los ciclos de cuentos a partir del nivel textual, paratextual y contextual para valorar qué elementos y cómo se combinan o anuncian el equilibrio entre la autonomía y la interrelación de los relatos. Explica que estos espacios contienen indicios sobre "el proyecto autorial de escritura; las exigencias del lector; [y] la producción material y comercialización del libro" (2000: 558). La interrelación de las partes del conjunto es definitiva pero alrededor y fuera de él gravitan este tipo de textos con funciones concretas que anticipan las señas de identidad de la modalidad. De acuerdo con Genette, son relevantes en la medida en que:

el texto raramente se presenta desnudo, sin el esfuerzo y el acompañamiento de un cierto número de producciones [...] que no sabemos si debemos considerarlas o no como pertenecientes al texto, pero que en todo caso lo rodean y lo prolongan precisamente por presentarlo, en el sentido habitual de la palabra, pero también en su sentido más fuerte: por darle presencia, por asegurar su existencia en el mundo, su recepción y su consumación, bajo la forma (al menos en nuestro tiempo) de un libro (2001: 7).

Compuesto por una heterogénea gama de manifestaciones textuales, icónicas, materiales y factuales, el paratexto ha sido clasificado, por su posición con respecto al texto, en dos categorías: peritextos y epitextos. La primera agrupa manifestaciones textuales e icónicas ubicadas alrededor del texto pero en el mismo espacio del libro e incluye partes como la información editorial textual (formato, colección, portadilla, tiraje) o icónica (portada, foto del autor, ilustraciones), información sobre el autor (nombre, título, dedicatorias, 
epígrafes, prefacios, intertítulos, seccionamientos) o comentarios de un tercero real o ficticio (introducciones, notas, epílogos). La segunda categoría, definida por Genette como epitexto, se compone por mensajes que gravitan fuera del espacio físico del libro; entre estos se distinguen epitextos públicos (boletines de prensa de la editorial, carteles, reseńas, entrevistas, conversaciones, coloquios debates) y privados (confidenciales e íntimos).

\section{Peritextos}

Los peritextos son útiles para identificar colecciones integradas ya que, como señala Miguel Gomes, "acompañan y 'hacen presente' a un volumen o una de sus piezas [...], han sido casi siempre seleccionados por el autor y tienen, no sólo por esa razón, y aunque parezca contradictorio, una importancia para nada marginal, puesto que orientan o lúdicamente desorientan nuestras lecturas" (567). Esta categoría comprende, entre otros, el nombre del autor, el título de la colección, los intertítulos, el índice, los epígrafes, las dedicatorias, los prefacios o posfacios, los seccionamientos y la datación o fechas de creación.

El nombre del autor anuncia que los relatos contenidos en el volumen fueron escritos por él mismo. Esta aparente obviedad toma sentido si por ejemplo pensamos en la antología donde aparecen los nombres de los distintos autores o del antologador. $\mathrm{Mu}$ chas antologías se asemejan a la colección de relatos integrados, la diferencia estriba precisamente en que la colección de relatos integrados es escrita y ordenada por un autor. Por lo demás este dato carece de mayor relevancia, sobre todo, si se piensa que el solo nombre del autor resulta una marca de identidad y unidad aplicable asimismo para las misceláneas de cuentos.

El título, en cambio, con frecuencia descubre el elemento de unidad o integración, organiza una colección, anuncia su conte- 
nido, orienta o condiciona su lectura y provee información genérica y temática relevante, de ahí que la mayoría de las colecciones integradas omiten en el título la tradicional coda " $\mathrm{y}$ otros cuentos", constante en varios volúmenes de cuentos misceláneos. Este peritexto primordialmente condensa y destaca la forma o el elemento de integración de los relatos en una colección. Según la tipología de Genette existen títulos remáticos, temáticos, mixtos y ambiguos. Los títulos remáticos en las colecciones integradas presentan designaciones genéricas, como es el caso de Cartas apócrifas (1997), de la panameña-nicaragüense Gloria Guardia; o también innovaciones genéricas como en el volumen Ucronias (1987), del mexicano Óscar de la Borbolla, que reúne una serie de relatos, publicados primero en diarios y revistas, que mezclan y confunden el discurso del reportaje periodístico con hechos ficticios, con el lúdico propósito de transformar la verosimilitud en veracidad. Estas dos colecciones desde el título privilegian la forma, la epístola y la ucronía respectivamente, como elemento de integración. Los títulos temáticos exponen otro tipo de elementos de integración como podría ser el espacio - De Zitilchén (1981), de Hernán Lara Zavala, o Todos Santos de California (2002), de Luis Felipe G. Lomelí-; un protagonista —Céfero (1961), de Xavier Vargas Pardo y Aventuras del detective Peter Pérez (1987), de Pepe Martínez de la Vega-; un conjunto de personas — Montevideanos (1959), de Mario Benedetti y Tijuanenses (1996), de Federico Campbell- o un motivo - Cuentos de color (1899), de Manuel Díaz Rodríguez.

Llama la atención que un número considerable de colecciones de relatos integrados presentan títulos mixtos, es decir, aquellos que combinan lo genérico-remático (cuentos, relatos, historias, ficciones) con lo temático (un personaje, una etapa en la historia de México, un pueblo mexiquense, una ciudad en las costas de Marruecos, un bar del norte de México o un etapa en la vida). Dentro de esta variedad podemos citar los Cuentos de Lilus Kikus 
(1954), de Elena Poniatowska; Relatos de la Revolución (1985), de Rafael F. Muñoz o Ficciones de la Revolución Mexicana (2009), de Ignacio Solares; Cuentos de Villahelada (1900), de Joaquín Gómez; Cuentos de Mogador (1994), de Alberto Ruy Sánchez; Historias del Lontananza (1997), de David Toscana, y Cuentos jóvenes (2004), de Hernán Lara Zavala, entre otros.

El título, como adelantamos, puede facilitar la localización de colecciones cuando desde esa instancia se promete algún tipo de unidad. Pienso, por ejemplo, en un grupo importante de cuentarios de difícil acceso que en el título abren la posibilidad de que el espacio, región o país sea considerado como elemento integrador de los relatos. En este espectro cabría mencionar colecciones como Cuentos de la pampa (1903) y Cuentos argentinos (1910), de Manuel Ugarte; Cuentos del Maule (1912), de Mariano Latorre; Cuentos andinos (1920), de Enrique López Albújar; Cuentos uruguayos (1920), de Adolfo Montiel Ballesteros; Chilenos del mar (1924), de Mariano Latorre; Cuentos chapines (1932), de Mariano Rodríguez Rossignon; Cuentos mexicanos (1936), de Francisco Monterde; Cuentos peruanos (1949), de Ventura García Calderón, o Cuentos venezolanos (1949), de Rómulo Gallegos. Es necesaria la lectura atenta de estas obras para corroborar si el título realmente corresponde al contenido de los cuentos o sólo se trata de una inercia o costumbre de la primera mitad del XX como fue la de asociar el género, en este caso el cuento, con el gentilicio; la cual se hizo poco usual a partir de la segunda mitad del siglo.

Los subtítulos, por su parte, refuerzan o llaman la atención también sobre la singularidad de la forma como sucede en Tiempo transcurrido. Crónicas imaginarias (1986), de Juan Villoro; Agua quemada. Cuarteto narrativo (1981) y La frontera de cristal. Una novela en nueve cuentos (1995), de Carlos Fuentes; Fronterizas. Una novela en seis cuentos (2001), de Roberta Fernández, o, volviendo a Óscar de la Borbolla, Asalto al infierno y otras aventuras ucrónicas 
(2005). Los subtítulos, en estos casos, tienden a resaltar la constitución de la obra: crónica imaginaria, cuarteto narrativo o novela compuesta con una serie de cuentos.

Los intertítulos subrayan la tensión entre la autonomía y la dependencia entre los relatos. Son una marca distintiva respecto a la novela contemporánea que generalmente ha optado por los numerar los capítulos, incorporar figuras o símbolos, u omitir cualquier tipo de registro. La función del intertítulo no sólo es descriptiva, su presencia recalca la independencia de la parte; es decir, la idea de que cada relato es un texto autónomo; en tanto el título del conjunto, como vimos, destaca uno o más atributos de integración. Lo anterior nos lleva a considerar que el título representa una marca de unidad, integración o totalidad y los intertítulos de diversidad, desintegración o valoración de la parte.

Los títulos de las secciones en una colección delimitan e integran subgrupos de relatos con patrones comunes que la crítica ha denominado microsecuencias (Mora, 1993), ciclos breves (Zavala, 2005) o minisecuencias de microrrelatos (Pollastri, 2006). Tal es el caso de las secciones de Historias de cronopios y famas (1962), de Julio Cortázar, tituladas "Manual de instrucciones", "Ocupaciones raras", "Material plástico" e "Historias de cronopios y famas"; de Simetrías (1993), de Luisa Valenzuela: "Cortes", "Mesianismos", "Cuentos de Hades" y "Tormentas"; o de Temporada de fantasmas (2004), de Ana María Shua: "En pareja”, "Misterios de la ficción”, "De la vida real", "Capricho divino", "Enfermedades", "Otros pueblos, otros mitos", "Dormir, soñar", "De la galera” y "El desorden sobrenatural de las cosas".

Los epígrafes y dedicatorias excepcionalmente son relevantes en una colección de relatos integrados. Sin embrago, en algunos casos, no dejan de aportar información relevante. Al respecto cabe mencionar que los epígrafes de la colección Cuentos de Eva Luna 
(1990), de Isabel Allende, ubicados al principio ${ }^{1}$ y al final, ${ }^{2}$ pertenecientes a Las mil y una noches, insertan a la colección en una tradición y ayudan a entenderla como una serie de cuentos enmarcados a la manera del Decamerón o Cuentos de Canterbury. La dedicatoria transparenta inclinaciones ideológicas o de filiación a un movimiento artístico, político o a un grupo de personas por parte del autor. Por ello, Lucía Etxebarría, por ejemplo, dedica Una historia de amor como otra cualquiera (2003) "A todas las mujeres que confiaron en mí para contarme sus historias" (5). Esta dedicatoria, cabe agregar, informa sobre el origen de las distintas historias que tienen en todos los casos a protagonistas femeninas.

De los peritextos anteriores, el prefacio resulta el espacio textual privilegiado por los escritores para explicar determinadas marcas distintivas de su colección de relatos. El prefacio ha sido definido como "toda especie de texto liminar (preliminar o posliminar) autoral o alógrafo, que constituye un discurso producido a propósito del texto que sigue o que precede" (Genette, 2001: 137). En una amplia variedad de libros puede reconocerse como introducción, prólogo, nota, noticia, aviso, presentación, preámbulo, advertencia, exordio, proemio, posfacio, epílogo, postscriptum o por títulos particulares. Sin desconocer los matices funcionales de cada uno de estos términos, los prefacios y posfacios, en general, dan cuenta de la génesis de la obra o la biografía del escritor; en ellos el autor o el editor despiertan expectativas o sugieren estrategias de decodificación. Los prefacios y posfacios pueden ser escritos por el propio autor, el editor o una tercera persona. Asimismo,

1 "El rey ordenó a su visir que cada noche le llevara una virgen y cuando la noche habría transcurrido mandaba que la matasen. Así estuvo haciendo durante tres años y en la ciudad no había ninguna doncella que pudiera servir para los asaltos de este cabalgador. Pero el visir tenía una hija de gran hermosura llamada Scherezade... y era muy elocuente y daba gusto oírla" (11).

2 "Y en ese momento de su narración Scherezade vio aparecer la mañana y se calló discretamente" (303). 
es posible que se presenten desde la perspectiva de un narradorpersonaje lo que, desde mi particular punto de vista, lo ubicaría dentro del nivel textual (normalmente se presentan como un texto que engloba o encierra a los demás). De cualquier forma son útiles para identificar la colección integrada pero, para no detenernos en una polémica sobre la pertenencia textual o paratextual de los prefacios ficcionales, analizaremos únicamente los prefacios autorales, ya que definen, describen o justifican una innovación genérica o estructural; otras veces enfatizan el hecho de que no se trata de un conjunto deshilvanado de relatos ni de una novela tradicional.

Así, Juan Villoro, en el prefacio "Rescate temporal”, de Tiempo transcurrido. Crónicas imaginarias (1986), fija y justifica el marco temporal de sus relatos, de 1968 a 1985, es decir, del movimiento estudiantil al terremoto de la Ciudad de México, y define la característica esencial del libro, mezcla de crónica y novela, de tal forma que "sirve a dos patrones: uno le da órdenes realistas, el otro fantásticas" (1986: 12). El prólogo de Doce cuentos peregrinos (1992), de acuerdo con Russell M. Cluff, "anuncia el propósito inicial del libro [y] el autor promete escribir una secuencia de cuentos" (2003: 341). En el "Prólogo. Por qué doce, por qué cuentos y por qué peregrinos", García Márquez explica el origen del proyecto y de cada uno de los cuentos, algunos de los cuales nacieron a partir de colaboraciones en periódicos o guiones de cine y televisión. No obstante, interesan específicamente dos observaciones que explicitan la intención de cohesionar las partes del volumen. Primero, cuando relata que el proyecto del libro partió de un sueño que tuvo, cuando radicaba en Barcelona, y que interpretó como una toma de conciencia sobre su identidad. Esta experiencia, nos dice, tuvo tal repercusión que la consideró un "buen punto de partida para escribir las cosas extrańas que les suceden a los hispanoamericanos en Europa” (1992: 14). El segundo apunte precisa la novedad de su cuarto libro de cuentos, pues especifica que ninguno 
de los tres anteriores "estaba concebido y resuelto como un todo" (1992: 15). En Guía triste de París (1999), Alfredo Bryce Echenique, incorpora al principio una "Nota del autor" donde, al igual que García Márquez, comenta el origen de sus cuentos: seis fueron publicados primero en periódicos como "Crónicas parisinas", otro fue un escrito por encargo de una editorial y el resto, dice, "no tiene más historia que la de su propia escritura” (2001: 8). Párrafos adelante destaca la singularidad del conjunto de los relatos por su carácter de guía, al afirmar que "guías prácticas hay, y buenas y malas, pero que yo sepa no existen guías tristes, y mucho menos de París" (8). El boricua Pedro Juan Soto en el "Prólogo" a la segunda edición de Spiks (1956) señala que "alguien ha observado que Spiks está concebida más como una novela que como libro de cuentos" (2001: 10) y más adelante agrega que aborda "la redacción de un libro de cuentos con sentido de integración, pensando en las partes como en el conjunto" (11). El "Prólogo" que Óscar de la Borbolla escribió para Asalto al infierno (2005), relata la génesis de su proyecto literario y comparte algunas notas biográficas al tiempo que delimita y define la singularidad de la colección. La ucronía, explica, comenzó en 1983 en el periódico Unomásuno como "una colaboración periodística que parecía verdadera porque confesaba ser falsa; que confundía por hacer vibrátil la verdad" (2005: 11) y en lo particular señala que Asalto al infierno reúne sus "aventuras ucrónicas, cuando fui corresponsal de lo imposible y reportero de mi mundo interior" (15).

Guillermo Cabrera Infante en Delito por bailar el chachachá (1995), a diferencia de los prefacios citados, recurre a un prólogo que titula "Tres en uno" y a un "Epílogo". El primero es una declaración de intenciones sobre el minimalismo y el recurso de la repetición en la música y la literatura. Menciona que la "literatura repetitiva trata de resolver la contradicción entre progresión y regresión al repetir la narración más de una vez" (1995: 13) y, por 
este motivo, más adelante en el mismo prefacio, señala que en los tres cuentos del libro el "tiempo es por supuesto diverso pero el espacio, la geografía [...] es la misma” (14). Ya en el "Epílogo" apunta que las historias "se funden o parece que se funden por compartir el mismo espacio al mismo tiempo" pero la singularidad recae en la modulación, concepto musical, que de acuerdo al autor es una "digresión del tono principal” (108).

Por último, Rodrigo Fresán en "Estado de gracias", posfacio de Historia Argentina, confiesa que "hay momentos en que no me cuesta ver todo esto como una suerte de novela desordenada bajo las preceptivas de cierta lógica secreta pero de ningún modo privada” (1993: 234).

Los peritextos editoriales, para bien o para mal, igualmente afectan las expectativas de lectura cuando las solapas o la contraportada arrojan "como primera conclusión que una de las partes del discurso invariablemente es la cuestión de la unidad" (Gomes, 2000: 573). Así, La frontera de cristal (1995), de Carlos Fuentes, es presentada por la editorial como novela compuesta por cuentos. En la contraportada podemos leer que en "esta novela (a través de nueve cuentos) Fuentes reproduce la separación que se ha dado entre México y Estados Unidos a lo largo de 200 años” y que los personajes están "unidos entre sí por las servidumbres y grandezas de una familia: los Barroso". De forma similar la contraportada de Hipotermia (2005), de Álvaro Enrigue, anuncia que es "una novela integrada por relatos, según intención del autor".

Otra facultad de la editorial consiste en etiquetar en un género la obra publicada; en el caso de colecciones de relatos muy cohesionadas es común encontrar la clasificación desde un género con mayores posibilidades de venta como lo es la novela. Lo anterior es perceptible en el caso de Fata Morgana, de Bruno Estañol, sobre la que pesan dos etiquetas en sus cuatro ediciones: novela y libro de cuentos. Para la primera (1989), la editorial Joaquín Mortiz la 
clasifica como "una novela sobre los ritos de iniciación de los adolescentes", adscripción que retoma la editorial Cal y Arena para la segunda edición, publicada en 1998. En la tercera (2002), el Fondo de Cultura Económica incluye la obra dentro de la antología de cuentos del autor; como ocurre también en la cuarta edición (2003), traducción al inglés publicada por Floricanto Press.

Debe considerarse que los parámetros editoriales a veces resultan meras artimañas comerciales, como sucede con Traficantes de belleza (1998), de Zoé Valdés, cuya solapa avisa que los quince cuentos "bien pudieran leerse también como una novela fragmentada", cuando en realidad resulta una colección tan débilmente cohesionada como un conjunto de cuentos misceláneos.

\section{Epitextos}

Los epitextos, como se mencionó, se encuentran afuera del espacio del libro. Gerard Genette los ubica:

En cualquier lugar fuera del libro; por ejemplo en diarios y revistas, emisiones de radio y televisión, conferencias y coloquios, todas producciones públicas eventualmente conservadas en registros o compilaciones impresas: entrevistas y conversaciones reunidas por el autor [...] o por un mediador [...], actas de coloquios, compilaciones de autocomentarios [...]. Incluso puede tratarse de testimonios contenidos en la correspondencia o diario de un autor, eventualmente dedicados a una publicación ulterior, ya sea previa o posterior a su muerte (295-296).

Las reseñas de libros y las monografías críticas, epitextos alógrafos, resultan un valioso recurso para detectar posibles colecciones de relatos integrados o para condicionar su lectura. $\mathrm{Al}$ presentar una visión panorámica y crítica de la obra, estos textos contemplan asuntos como la organización, el estilo, el tema y las estrategias 
literarias relativas a la integración o desintegración de las partes como puede comprobarse en dos reseñas seleccionadas a propósito. José Miguel Oviedo comenta sobre Travesuras de la niña mala (2006), de Mario Vargas Llosa, que:

Aunque los personajes sean los mismos y el hilo de su relación amorosa se mantenga pese a los distintos lugares donde van a parar, los sucesos de cada capítulo tienden a presentarse con cierta autonomía narrativa: tienen un ambiente específico, personajes secundarios que no vuelven a aparecer, incidentes dispuestos para funcionar in situ y un cierre bastante definitivo. [...] La naturaleza tan episódica de cada capítulo (subrayada por el hecho de que llevan títulos) genera una soberanía que bordea con el cuento o sugiere una novela escrita a partir de secuencias concebidas casi independientemente (2006: internet).

En términos similares, Christopher Domínguez Michael se refiere a Hipotermia, de Álvaro Enrigue:

Ante Hipotermia el editor y el lector, como el propio Enrigue, se sienten tentados a buscar una supuesta hibridez que lo acercaría a la novela [ya que] a una sola clase de personaje [...] se encomienda como narrador de la mayoría de sus historias: ese escritor a la vez fracasado y al mismo tiempo dueńo de todos los hilos de la comedia que es él mismo, es decir, su alter ego (2006: internet).

Las reseńas de Oviedo y Domínguez Michael demuestran que, aunque en ocasiones el crítico pasa por alto u omite las denominaciones usuales de esta modalidad narrativa, sí describen de manera precisa la singularidad de la estructura y las tensiones entre autonomía y dependencia: Oviedo analiza la obra de Vargas Llosa desde la perspectiva de la novela pese a la "nitidez episódica" y casi autónoma de los capítulos; Domínguez Micheal destaca la ten- 
tación de editor y lector de leer y entender Hipotermia como un híbrido cercano a la novela.

Respecto al epitexto autoral público, puede citarse a Carlos Fuentes, no tanto por ser un escritor bien identificado por muchos lectores sino porque en sus declaraciones y su producción cuentística encontramos una constante intención de relacionar relatos. Obras como Agua quemada (1984), El naranjo o los círculos del tiempo (1993), La frontera de cristal (1994), Inquieta compañia (2004) y Todas las familias felices (2006) revelan diferentes tipos y niveles de integración que Fuentes se ha encargado de subrayar a través de sendas entrevistas. En 1996 le explicaba a Ricardo Cayuela que la estructura abierta de La frontera de cristal es heredera de obras de escritores como Balzac, Sherwood Anderson y James Joyce:

Se trata de la vieja enseñanza balzaciana del eterno retorno de los pesonajes. Yo creo que libros como Winesburg, Ohio de Sherwood Anderson [...], ofrecen al lector la posibilidad de permanecer con una historia abierta e inacabada, en la que siente que no se ha dicho la última palabra. Libros en los que sólo un perfume, una atmósfera, reúne todos los cuentos. Es el caso de Winesburg, Ohio y de Dublineses de Joyce, en los que hay muchas menos ligas de unión entre los cuentos que en el mío. Estos libros te dejan con la sensación de haber pertenecido al mundo contenido en sus páginas, pero del que sólo te entregan una apertura, una "inconclusión" a sus propias historias. En La frontera de cristal más que buscar la unidad entre los cuentos se trata de llegar a un conjunto, sí, pero inconcluso, que te permita seguir recreando las posibilidades narrativas que involucra su propio inacabamiento (1991: 257).

Posteriormente, respecto a Todas las familias felices (2006), puntualiza la particularidad de la colección desde la indefinición genérica: 
$[\mathrm{N}]$ o puede clasificarse, desde luego, como una novela, pero tampoco como un libro de cuentos, están ligados por los coros y lo que hay es una narración coral, yo la llamo así. Son relatos en apariencia individuales pero ligados a una realidad colectiva y están relacionados, a la manera de Balzac, con el regreso de personajes de cuentos anteriores y de cuentos que siguen, y esto crea un universo distinto. He intentado construir una narrativa coral, que se responde y dialoga consigo misma en todos sus segmentos y por ello es diferente del cuento aislado y de la novela, y hay que leerlo como una expresión de la individualidad y de la colectividad (Blanco, 2007: internet).

Tales antecedentes afectan la lectura de La frontera de cristal y Todas las familias felices. Así, la biografía del escritor, lo que ha dicho, leído o escrito sin duda enfocan la interpretación de una colección integrada y lo mismo podría decirse del contexto social o histórico de la obra.

Para cerrar conviene insistir que ningún paratexto define a una colección de relatos integrados aunque contengan claves características. Como vimos, condicionan o resaltan ciertos recursos que adelantan la perspectiva de unidad o diversidad. Así, por ejemplo, mientras el título subordina los relatos a una forma de integración, los intertítulos se encargan de enfatizar su condición autónoma. Los prefacios y posfacios como espacios privilegiados concentran el mayor número de evidencias sobre las tensiones propias de la modalidad estudiada. Sobre este punto llama la atención que la mayoría de descripciones y declaraciones de intención son más comunes entre escritores consolidados como en los casos revisados de Gabriel García Márquez, Alfredo Bryce Echenique, Juan Villoro, Rodrigo Fresán y Guillermo Cabrera Infante. En cuanto a los paratextos editoriales, básicamente los textos de contraportada o solapas, habría que considerarlos con reservas pero no desdeñarlos porque en poco tiempo puede tenerse una idea del volumen que 
está en nuestras manos, lo que posiblemente evitaría un gasto innecesario; así, desde esta perspectiva, también respalda su función.

\section{Bibliografía}

Allende, Isabel, 1990, Cuentos de Eva Luna, Barcelona, Plaza y Janés.

Blanco, María Luisa, 2007, "Carlos Fuentes: decir la violencia”, El Nuevo Diario, 3 de enero, en: http://www.elnuevodiario.com. ni/2006/02/24/cultural/30803

Borbolla, Óscar, 2005, Asalto al infierno y otras ucronías, México, Nueva Imagen.

Bryce Echenique, Alfredo, 2001, Guía triste de París, 2a ed., Madrid, Punto de lectura.

Cabrera Infante, Guillermo, 1995, Delito por bailar el chachachá, Madrid, Punto de Lectura.

Cayuela Gally, Ricardo, 1991, "Nuevo tiempo mexicano", en Jorge F. Hernández (ed.), Carlos Fuentes: Territorios del tiempo. Antología de entrevistas, México, FCE, pp. 253-265.

Cluff, Russell M., 2003, Los resortes de la sorpresa (Ensayos sobre el cuento mexicano del siglo XX), Tlaxcala, Universidad Autónoma de Tlaxcala / Brigham Young University.

Domínguez Michael, Christopher, 2006, "Hipotermia, de Álvaro Enrigue", Letras Libres, núm. 86, febrero, en: http://www.letraslibres.com/index.php?art=11061

Dunn, Maggie y Ann Morris, 1995, The Composite Novel. The Short Story in Transition, Nueva York, Twayne Publishers.

Etxebarria, Lucía, 2004, Una historia de amor como otra cualquiera, Barcelona, Planeta DeAgostini.

Enrigue, Álvaro, 2005, Hipotermia, Barcelona, Anagrama,. 
Fresán, Rodrigo, 1993, Historia Argentina, Barcelona, Anagrama.

Fuentes, Carlos, 1994, La frontera de cristal, México, Alfaguara.

García Márquez, Gabriel, 1992, Doce cuentos peregrinos, Madrid, Mondadori.

Gomes, Miguel, 2000, "Para una teoría del ciclo de cuentos hispanoamericano", Rilce. Revista de Filología Hispánica, núm. 16, año 3, pp. 557-583.

Genette, Gerard, 2001, Umbrales, Susana Lage (trad.), México, Siglo XXI.

Ingram, Forrest L., 1971, Representative Short Story Cycles of the Twentieth Century. Studies in a Literary Genre, París / La Haya, Mouton.

Kennedy, J. Gerald, 1995, Modern American Short Story Sequences. Composite Fictions and Fictive Communities, Cambridge, Cambridge University Press.

Leal, Luis, 2006, "El cuento mexicano de estructura integrada", en Pablo Brescia y Evelia Romano (comps.), El ojo en el caleidoscopio, México, UNAM, pp. 143-162.

Lundén, Rolf, 1999, The United Short Stories of America. Studies in the Short Story Composite, Amsterdam / Atlanta, Rodopi.

Luscher, Robert M., 1989, “The Short Story Sequence: An Open Book", en Susan Lohafer y Jo Ellyn Clarey (eds.), Short Story Theory at a Crossroads, Baton Rouge, Louisiana State University Press, pp. 148-167.

Mann, Susan Garland, 1989, The Short Story Cycle. A Genre Companion and Reference Guide, Nueva York / Westport / Londres, Greenwood Press.

Mora, Gabriela, En torno al cuento: de la teoría general y de su práctica en Hispanoamérica, Buenos Aires, Danilo Alberto-Vergara. 
Oviedo, José Miguel, 2006, “Reflexiones de la niña mala”, Letras Libres, núm. 98, julio, en: http://www.letraslibres.com/index. php?art=11369.

Pollastri, Laura, 2006, "Desordenar la biblioteca: microrelato y ciclo cuentístico", en Pablo Brescia y Evelia Romano (comps.), El ojo en el caleidoscopio, México, UNAM, pp. 79-114.

Soto, Pedro Juan, 2001, Spiks, 2a ed., San Juan de Puerto Rico, Editorial Cultural.

Villoro, Juan, 1986, Tiempo transcurrido. Crónicas imaginarias, México, FCE.

Zavala, Lauro, 2005, La minificción bajo el microscopio, Bogotá, Universidad Pedagógica Nacional. 